\title{
Disability in progressive MS is associated with T2 lesion changes
}

\section{Ammitzbøll, Cecilie ; Dyrby, Tim Bjørn; Lyksborg, Mark; Schreiber, K.; Ratzer, R.; Christensen, J. Romme; Iversen, P.; Magyari, M.; Garde, E.; Sørensen, P. S.}

Total number of authors:

12

Published in:

Multiple Sclerosis and Related Disorders

Link to article, DOI:

10.1016/j.msard.2017.12.010

Publication date:

2017

Document Version

Peer reviewed version

Link back to DTU Orbit

Citation (APA):

Ammitzbøll, C., Dyrby, T. B., Lyksborg, M., Schreiber, K., Ratzer, R., Christensen, J. R., Iversen, P., Magyari, M., Garde, E., Sørensen, P. S., Siebner, H. R., \& Sellebjerg, F. (2017). Disability in progressive MS is associated with T2 lesion changes. Multiple Sclerosis and Related Disorders, 20, 73-77. https://doi.org/10.1016/j.msard.2017.12.010

\section{General rights}

Copyright and moral rights for the publications made accessible in the public portal are retained by the authors and/or other copyright owners and it is a condition of accessing publications that users recognise and abide by the legal requirements associated with these rights.

- Users may download and print one copy of any publication from the public portal for the purpose of private study or research.

- You may not further distribute the material or use it for any profit-making activity or commercial gain

- You may freely distribute the URL identifying the publication in the public portal 


\section{Author's Accepted Manuscript}

Disability in progressive MS is associated with T2 lesion changes

C. Ammitzbøll, TB. Dyrby, M. Lyksborg, K. Schreiber, R. Ratzer, J. Romme Christensen, P. Iversen, M. Magyari, E. Garde, PS. Sørensen, HR. Siebner, F. Sellebjerg

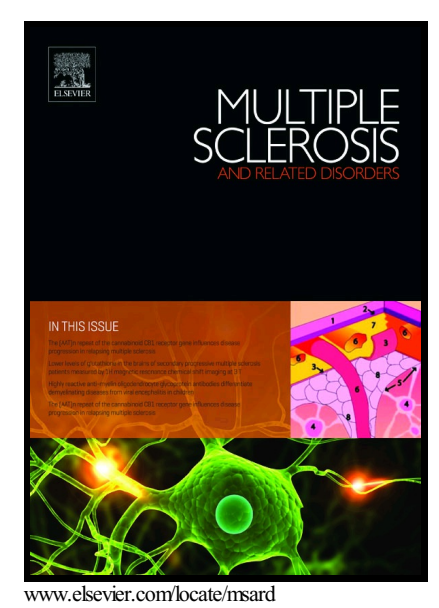

PII: S2211-0348(17)30350-4

DOI: $\quad$ https://doi.org/10.1016/j.msard.2017.12.010

Reference: MSARD724

To appear in: Multiple Sclerosis and Related Disorders

Received date: 21 September 2017

Revised date: 17 November 2017

Accepted date: 15 December 2017

Cite this article as: C. Ammitzbøll, TB. Dyrby, M. Lyksborg, K. Schreiber, R. Ratzer, J. Romme Christensen, P. Iversen, M. Magyari, E. Garde, PS. Sørensen, HR. Siebner and F. Sellebjerg, Disability in progressive MS is associated with T2 lesion changes, Multiple Sclerosis and Related Disorders, https://doi.org/10.1016/j.msard.2017.12.010

This is a PDF file of an unedited manuscript that has been accepted for publication. As a service to our customers we are providing this early version of the manuscript. The manuscript will undergo copyediting, typesetting, and review of the resulting galley proof before it is published in its final citable form. Please note that during the production process errors may be discovered which could affect the content, and all legal disclaimers that apply to the journal pertain. 


\section{Disability in progressive MS is associated with T2 lesion changes}

Ammitzbø\|ll $\mathrm{C}^{1}$, Dyrby $\mathrm{TB}^{2,3}$, Lyksborg $\mathrm{M}^{3}$, Schreiber $\mathrm{K}^{1}$, Ratzer $\mathrm{R}^{1}$, Romme Christensen $\mathrm{J}^{1}$, Iversen $\mathrm{P}^{2}$, Magyari $\mathrm{M}^{1}$, Garde $\mathrm{E}^{2,4}$, Sørensen $\mathrm{PS}^{1}$, Siebner $\mathrm{HR}^{2,5}$, Sellebjerg $\mathrm{F}^{1}$

${ }^{1}$ Danish Multiple Sclerosis Center, University of Copenhagen, Rigshospitalet, Copenhagen, Denmark, ${ }^{2}$ Danish Research Centre for Magnetic Resonance, Centre for Functional and Diagnostic Imaging and Research, Copenhagen University Hospital Hvidovre, Hvidovre, Denmark. ${ }^{3}$ Department of Applied Mathematics and Computer Science, Technical University of Denmark, Lyngby, Denmark; ${ }^{4}$ Faculty of Health and Medical Sciences, Center for Healthy Aging, University of Copenhagen, Copenhagen, Demark, ${ }^{5}$ Department of Neurology, University of Copenhagen, Bispebjerg Hospital, Copenhagen, Denmark

\section{Corresponding author:}

Cecilie Ammitzbøll

Danish Multiple Sclerosis Centre

Rigshospitalet, University of Copenhagen

Blegdamsvej 9, DK- 2100 Copenhagen

Direct phone: +4535456392

Cell phone: +4521235202

Fax: +4535456316

Email: cecilie.ammitzboell@regionh.dk 
Key words: Magnetic resonance imaging, multiple sclerosis, magnetisation transfer ratio, diffusion tensor imaging, expanded disability status scale, multiple sclerosis functional composite 


\section{Abstract}

Background: Progressive multiple sclerosis (MS) is characterized by diffuse changes on brain magnetic resonance imaging (MRI), which complicates the use of MRI as a diagnostic and prognostic marker. The relationship between MRI measures (conventional and non-conventional) and clinical disability in progressive MS therefore warrants further investigation.

Objective: To investigate the relationship between clinical disability and MRI measures in patients with progressive MS.

Methods: Data from 93 primary and secondary progressive MS patients who had participated in 3 phase 2 clinical trials were included in this cross-sectional study. From 3T MRI baseline scans we calculated total T2 lesion volume and analysed magnetisation transfer ratio (MTR) and the diffusion tensor imaging indices fractional anisotropy (FA) and mean diffusivity (MD) in T2 lesions, normalappearing white matter (NAWM) and cortical grey matter. Disability was assessed by the Expanded Disability Status Scale (EDSS) and the MS functional composite.

Results: T2 lesion volume was associated with impairment by all clinical measures. MD and MTR in T2 lesions were significantly related to disability, and lower FA values correlated with worse hand function in NAWM. In multivariable analyses, increasing clinical disability was independently correlated with increasing T2 lesion volumes and MTR in T2 lesions.

Conclusion: In progressive MS, clinical disability is related to lesion volume and microstructure. 


\section{Introduction}

Specific changes on brain MRI are usually seen in patients with MS, and MRI is a valuable tool for diagnosing MS and for monitoring disease activity even though the clinical correlate is modest $(1,2)$. Disease worsening in MS is associated with increased lesion volume, decreased brain volume and changes in normal appearing white matter (NAWM) $(2,3)$. In progressive MS, contrast enhancing lesions occur less frequently than in relapsing remitting MS (RRMS), whereas diffuse NAWM and grey matter abnormalities are more pronounced (4). Therefore, the correlation between MRI and disease worsening in progressive MS is even more complex.

Non-conventional MRI including magnetisation transfer imaging and diffusion tensor imaging (DTI) is sensitive to diffuse microstructural tissue abnormalities and is therefore a promising tool in the monitoring of MS $(3,5)$. The magnetisation transfer ratio (MTR) quantifies the energy transfer between tissue-bound protons and free water protons by stimulation of the tissue with an extra off-frequency magnetic pulse. MTR is sensitive to changes in myelin content and has also been found associated with axonal loss $(1,3,6)$. DTI provides indices that from the scattering of water molecules within the microstructural environment describe the degree of anisotropy determined by overall hindrance and restrictions. The mean diffusivity (MD) is a measure of the overall mobility of water molecules, and fractional anisotropy (FA) is a measure of the degree of microstructural alignment in a voxel (7). Changes in MD and FA correlate with demyelination and axonal loss in MS $(3,8,9)$.

In the present study we investigated the association of clinical disability and MRI measures, both conventional and non-conventional, in progressive MS. For the evaluation of clinical disability we used the expanded disability status scale (EDSS) as well as the multiple sclerosis functional composite (MSFC) which has the advantage of including a cognitive component, the paced auditory serial addition test (PASAT) $(10,11)$. We hypothesized that tissue structure in normal-appearing white matter (NAWM) and cortical grey matter (CGM) as assessed by non-conventional MRI measures 
would complement the conventional lesion volume measurements in predicting clinical disability. We did, however, find that overall clinical disability correlated mainly with T2 lesion volume and MTR and DTI measures in T2 lesions.

\section{Methods}

\subsection{Study population}

We conducted a cross-sectional study in a cohort of 93 patients with progressive MS. MRI data were obtained from baseline visits from three different clinical trials in the period from February 2010 to June 2012. We studied data from 24 patients who participated in a trial with natalizumab, 52 patients who participated in a trial with erythropoietin and 30 patients who participated in a trial with methylprednisolone (12-14). For patients participating in more than one trial, the baseline data from the first trial was used, unless a more complete data set was assessable from a subsequent trial. Inclusion criteria for the natalizumab and methylprednisolone trials included age of 18 to 65 years (18 to 55 years in the natalizumab trial), SPMS or PPMS diagnosed according to the 2005 revision of the McDonald criteria (15), EDSS score $\leq 6.5$ and progression the last 2 years of $\geq 1$ EDSS point $(\geq 0.5$ if baseline EDSS score was $\geq 5.5$ ). In the methylprednisolone trial the inclusion criteria were also met with a progression the last two years of two functional system points. Exclusion criteria for both trials were relapses the previous month or immunomodulatory or immunosuppressive treatment, respectively, 3 and 6 months prior to first visit. In the erythropoietin trial, inclusion criteria were age 19 to 60 years, SPMS or PPMS diagnosed according to the 2005 revision of the McDonald criteria, EDSS score 4 to 6.5 , progression without relapses the last 2 years of $\geq 0.5$ EDSS point and MRI verifying MS according to the Barkhof criteria. Exclusion criteria were comorbidities, immunomodulatory or immunosuppressive treatment 1 or 6 months prior to first visit, respectively (14). More detailed inclusion and exclusion criteria are presented in the respective studies (12-14). All patients gave 
written informed consent to participation, and all studies were approved by the local scientific ethics committee. Clinical scores of EDSS and MSFC, including 9 hole peg test (9HPT), timed 25 foot walk (T25FW) and PASAT were performed by trained and EDSS-certified physicians.

\subsection{MRI}

All scans were performed on a 3T Siemens Trio MRI scanner (Siemens, Germany) as previously described in detail (12). Regions of interest (ROI) were T2 white matter lesions, NAWM and CGM. Based on T2-weighted images, lesion volumes were manually segmented by experienced personnel using Jim software (Xinapse systems, UK). In addition, NAWM and CGM segmentation volumes were determined using SIENAX (FSL software). For each segmentation volume, a summary statistic of interest was estimated for each of the image modalities MTR, MD and FA as previously described in detail (12).

\subsection{Statistical analysis}

Student t-test was used with normally distributed data and parametric or non-parametric correlation analyses were performed with continuous data according to the distribution of data. Univariate analysis of variance (ANOVA) was used when adjustment of co-variates and co-factors were done. In parametric analyses, logarithmically transformed values for T2 lesion volume were used. For the multivariable assessment of the relationship between disability and MRI variables ANOVA with bootstrapping was used since the clinical data could not be mathematically transformed to normal distributed values. False discovery rate correction was applied to account for multiple comparisons in all correlation analyses (16). A false discovery rate q-value $<0.05$ was considered statistically significant, whereas a nominally significant $p$-value $<0.05$ only was considered as suggestive. Statistical analyses were performed using SPSS software version 22 (IBM, USA). 


\section{Results}

\subsection{Demographic characteristics and MRI}

We analysed cross-sectional data from 93 patients with progressive MS. Thirty-seven patients had primary progressive MS (PPMS) and 56 patients had secondary progressive MS (SPMS).

Demographic data are given in table 1. The disease duration was longer for patients with SPMS than for patients with PPMS $(p<0.001)$, but the progression duration was comparable in the two groups. No significant differences in age or sex were found in patients with PPMS compared with patients with SPMS. We first investigated associations of type of progressive disease, age, sex, disease duration and progression duration with MRI measures and found that MD in T2 lesions differed with MS type as patients with PPMS had lower MD values than patients with SPMS ( $p=0.003, q=0.027$ ) (table 2). T2 lesion volume was lower in patients with PPMS compared with patients with SPMS, but this finding was not significant after correction for multiple comparisons $(p=0.016, q=0.080)$. We found lower FA values in CGM in men than in women $(p<0.001, q=0.002)$ and, finally, disease duration but not progression duration correlated with most MRI variables, i.e., T2 lesion volume ( $r=0.363, p=0.001$, $q=0.004)$, MTR in lesions $(r=-0.314, p=0.004, q=0.006)$, MD in lesions $(r=0.454, p<0.001, q<0.001)$, MTR in NAWM ( $r=-0.344, p=0.001, q=0.004)$, FA in NAWM $(r=-0.318, p=0.003, q=0.005)$, MD in NAWM $(r=0.235, p=0.028, q=0.041)$ and MD in CGM $(r=0.350, p=0.001, q=0.003)$. Disease duration did not correlate with FA in lesions, FA in CGM or MTR in CGM.

\subsection{Clinical disability is mainly associated with brain T2 lesions}

In order to examine how MRI is associated with clinical disability, we analysed the relationship between clinical disability scores and MRI measures. We found a statistically significant relationship between increasing $\mathrm{T} 2$ lesion volume and worse scores for all clinical disability measures: a positive 
correlation with EDSS $(\rho=0.286, q=0.043)$, 9HPT $(\rho=0.312, q=0.041)$ and T25FW $(\rho=0.313, q=0.047)$ and a negative correlation with PASAT scores $(\rho=-0.303, q=0.044)$ (table 3).

Within T2 lesions, we found a negative correlation between MTR values and EDSS scores $(\rho=-0.278$, $q=0.048)$, while increasing MD values in T2 lesions correlated with higher T25FW values $(\rho=0.278$, $q=0.049)$ and reduced PASAT scores $(\rho=-0.356, q=0.025)$.

In NAWM, decreasing FA values correlated with increasing 9HPT values $(\rho=-0.359, q=0.043)$ (table 3). We found no significant correlations with clinical disability measures for FA in lesions, MD or MTR in NAWM or for FA, MD or MTR in CGM.

Regarding the EDSS, the strongest correlation was observed with T2 lesion volume; for the 9HPT the strongest correlation was observed with FA values in NAWM; for the T25FW the strongest correlation was observed with T2 lesion volumes; and for the PASAT the strongest correlation was observed with MD values in T2 lesions. In a multivariable analysis increasing EDSS scores were independently associated with increasing T2 lesion volumes $(p=0.008)$ and decreasing MTR in T2 lesions $(p=0.02)$ (ANOVA with bootstrapping). For the 9HPT, the T25FW and the PASAT we found no additional MRI measures to be independently associated in multivariable analyses (data not shown).

\section{Discussion}

In the present study, we found that larger T2 lesion volumes correlate with increased disability in progressive MS and that increased MD and decreased MTR in T2 lesions are also associated with disability. In addition, in NAWM decreased FA values correlate with reduced 9HPT scores.

The present study is one of the largest studies to evaluate the relationship between MRI changes and disability in progressive MS. Yet several issues need to be taken into account when interpreting these results. We analysed data from patients with SPMS and PPMS together in order to have a large 
cohort of patients providing sufficient statistical power. Indeed, only minimal differences in MRI results were found between the two progressive MS subtypes,but we cannot rule out that the inclusion of larger numbers of patients might have revealed more differences between PPMS and SPMS. Patients included in the study were characterised by clinical disease progression which made them eligible for participation in the clinical trials. Thus, the cohort represents a selected subgroup of patients with clear disease progression and preserved ambulatory function. Furthermore, there will be inter-patient variability in disability scores independent of MS severity. Particularly the PASAT scores must be expected to show variation according to basic cognitive skills. Regarding progressive MS, it would have been interesting to study how grey matter lesions correlate with disability. However, as we did not use ultra-high field 7T MRI or included double- or phase sensitivity inversion recovery imaging in the present study, we were not able to differentiate grey matter lesions from normal-appearing grey matter. This may lead to an underestimation of the relationship between grey matter pathology and disability. Accordingly, in a recent study of a combined SPMS/RRMS cohort, MTR and FA values were lower and MD values higher in cortical lesions than in non-lesional cortex. Significant correlations between disability measures and MTR and DTI indices in this study were observed for both lesional and extra-lesional CGM (17).

In the initial analyses, we would have expected age to be associated with most MRI measures as previously reported (18). We attribute this negative finding to the fact that the age range of the included patients was narrow, rendering the analysis insensitive to any age related effect. In contrast, disease duration had a wider range in our patient cohort and was associated with most MRI measures. The finding of sex being associated with FA in CGM is interesting and has to our knowledge not been previously described. However, it is difficult to infer the implications of this finding in terms of pathophysiology given the design of the present study. 
Hyperintense lesions on T2-weighted imaging are conventionally used as a MRI measure of burden of disease, but T2 lesions are only moderately correlated with disability in MS $(2,19)$. In addition to the importance of the location of the individual lesions, the reason for this modest correlation appears to be the heterogeneous pathological changes found in T2 lesions. Histopathology studies describe T2 lesions having variable degrees of inflammation, demyelination, axonal loss, remyelination and oedema, and the distinction between these is not possible with conventional T2-weighted MRI $(5,20)$. Despite this reservation, $\mathrm{T} 2$ lesions were reported to be associated with disability also in progressive MS $(21,22)$. In the present study total T2 lesion volumes were consistently and comparably associated with disability assessed by 9HPT, T25FW, EDSS and PASAT scores. This suggests that the bias of the 9HPT and EDSS score for assessing hand and leg function is not a sufficient explanation for the poor correlation between T2 lesion volumes and disability usually observed. Nevertheless, the inclusion of spinal cord MRI has been shown to explain an additional proportion of the disability in MS $(23,24)$. In accordance with our findings, an association of T2 lesions with cognitive impairment and reduced performance in the PASAT was previously reported for patients with PPMS and SPMS $(25,26)$.

Not only T2 lesion volume, but also T2 lesion MTR values were associated with disability in the present study. MTR values in lesions correlated negatively with EDSS scores, and this was statistically independent of the T2 lesion volume effect in a multivariable analysis. As low MTR values are associated with demyelination, this measure was expected to be altered in T2 lesions, but the independent relationship with disability in progressive MS is a novel finding $(27,28)$. Our results therefore confirm and extend the results from a previous study in a combined cohort of patients with RRMS and SPMS, which reported reduced MTR values in white matter lesions and a non-significant trend to correlation with disability (21). 
Previous DTI studies of T2 lesions in patients with MS revealed that increased MD and reduced FA values are also associated with demyelination and axonal loss $(1,8)$. In SPMS, but not PPMS, increased MD and reduced FA values in T2 lesions were previously found to be associated with physical impairment as assessed by the EDSS (29). In accordance with these findings, we found increased MD in T2 lesions to correlate with reduced performance in T25FW and PASAT, but we did not find a significant correlation between FA in T2 lesions and disability.

To assess a more sensitive and discriminative measure of localized tissue pathology and relation to specific functional disability, tract-based analyses with anatomical connectivity mapping would be preferable, but we found it to be beyond the scope of the present study to perform these analyses (30).

In progressive MS, brain tissue changes are characterised by cortical grey matter lesions, diffuse alterations in NAWM and slowly expanding white matter lesions. These changes differ from the focal white matter lesions characterising RRMS pathology (31). We expected, in this cohort of patients with progressive MS, that the use of MTR and DTI would enable us to detect such diffuse tissue alterations in NAWM and CGM and that it would be related to clinical disability. Consistent with these expectations, we found reduced FA values in NAWM to correlate with worse outcome in the 9HPT, EDSS and T25FW, but only the correlation with 9HPT was significant after correction for multiple testing. We found no significant correlations between MTR or MD in NAWM with clinical measures apart from a trend to worse 9HPT scores with increased MD and reduced MTR. Neither did we find MTR or DTI measures to correlate with disability in CGM, apart from a trend to worse 9HPT scores with increased MD and reduced MTR and FA. As discussed above this might reflect that we analysed CGM in total rather than as lesional and non-lesional CGM, as well as partial volume effects. As for the T2 lesions, the limited correlation between clinical disability and MTR and DTI indices in CGM and NAWM may also reflect that we did not discriminate between changes in eloquent and non-eloquent 
brain areas. Finally, there is a possibility that we induced type 2 errors in our statistical hypothesis testing, thereby neglecting real differences. This could be a consequence of lack of power for the statistical analyses due to the size of the patient cohort.

To summarise, we found that in progressive MS, T2 lesion volume and structure is associated with physical and cognitive impairment. These findings are interesting as T2 lesions in progressive MS are generally believed to be mostly of the slowly expanding or inactive type, and we therefore speculate that the slowly expanding T2 lesions are associated with disability progression $(31,32)$. MTR and MD changes in T2 lesions were also associated with disability. Whether this is due to ongoing demyelination and axonal loss or a lack of remyelination remains to be clarified, and so far the 3T imaging technology is not capable of providing the contrast needed to differentiate between these situations. Overall, MTR and MD changes in NAWM and CGM were less clearly associated with disability, which was unexpected, as progressive MS is characterised by diffuse changes in these tissues.

\section{Acknowledgments}

This study was supported by grants from the Danish MS Society [R308 A19240]. The authors wish to thank the excellent staff at the The Danish Research Centre for Magnetic Resonance, Sussi Larsen, Sascha Gude and Hanne Schmidt for the execution and handling of MRI sequences. We also wish to thank the excellent nurses, Vibeke Jespersen, Sidsel Nielsen and Joan Pietraszek at the Danish Multiple Sclerosis Center for the professional and kind assistance in patient logistics and care.

\section{Authorship and Conflict-of-Interest Statements}

Contribution: C.A. wrote the first draft of the paper. F.S., H.R.S., T.D., P.I., E.G. and C.A. designed the present study. F.S., P.S.S., K.S., J.R.C., R.R., T.D., P.I., E.G. and H.R.S designed included studies. J.R.C., R.R., M.M. and K.S. performed the clinical evaluations. T.D., M.L., P.I. and E.G. 
performed MRI. T.D., M.L., P.I., E.G., J.R.C., R.R., K.S., F.S. and C.A. analyzed the data. All authors contributed to revising and finalizing the manuscript.

Conflict-of-interest disclosure: C.A. has had travel expenses reimbursed by Genzyme, Merck Serono, Teva and Biogen Idec. K. S. has received support for congress participation from Biogen Idec, Genzyme, Merck Serono, Novartis and Teva, and served on advisory board for Novartis. R.R. has had travel expenses reimbursed by Biogen Idec and Genzyme. J.R.C. has had travel expenses reimbursed by Novartis. P. I. has received meeting registration fees and speaker honoraria from Biogen Idec. E.G. has received speaker honoraria and has had travel expenses reimbursed by Biogen Idec. P.S.S has received personal compensation for serving on scientific advisory boards, steering committees or independent data monitoring boards for Biogen Idec, Merck Serono, Novartis, Genzyme, Teva Pharmaceutical Industries Ltd., GlaxoSmithKline, medDay Pharmaceuticals and Forward Pharma and has received speaker honoraria from Biogen Idec, Merck Serono, Teva Pharmaceutical Industries Ltd., Genzyme, and Novartis. H.R.S. has served on a scientific advisory board for Lundbeck A/S, Valby Denmark, and has received honoraria as speaker from Biogen Idec, Genzyme, and Merck Serono, has received honoraria as editor from Elsevier Publishers, and Springer Publishing, has received travel support from MagVenture, and has received a research fund from Biogen Idec. F.S. has served on scientific advisory boards, been on the steering committees of clinical trials, served as a consultant, received support for congress participation, received speaker honoraria, or received research support for his laboratory from Biogen, EMD Serono, Genzyme, Lundbeck, Merck Serono, Novartis and Teva. M.M: has served on scientific advisory board for Biogen, Sanofi, Teva, Roche, Novartis, Merck, has received honoraria for lecturing from Biogen Idec, Merck, Novartis, Sanofi, has received support for congress participation from Biogen, Novartis, Genzyme and Teva. T.D. and M.L. reports nothing to disclose. 


\section{References}

1. Miller TR, Mohan S, Choudhri AF, Gandhi D, Jindal G. Advances in multiple sclerosis and its variants: conventional and newer imaging techniques. Radiologic clinics of North America. 2014;52(2):321-36.

2. Wattjes MP, Rovira A, Miller D, Yousry TA, Sormani MP, de Stefano MP, et al. Evidence-based guidelines: MAGNIMS consensus guidelines on the use of MRI in multiple sclerosis--establishing disease prognosis and monitoring patients. Nature reviews Neurology. 2015;11(10):597-606.

3. Enzinger C, Barkhof F, Ciccarelli O, Filippi M, Kappos L, Rocca MA, et al. Nonconventional MRI and microstructural cerebral changes in multiple sclerosis. Nature reviews Neurology. 2015;11(12):676-86.

4. Antel J, Antel S, Caramanos Z, Arnold DL, Kuhlmann T. Primary progressive multiple sclerosis: part of the MS disease spectrum or separate disease entity? Acta neuropathologica. 2012;123(5):627-38.

5. Filippi M, Rocca MA, De Stefano N, Enzinger C, Fisher E, Horsfield MA, et al. Magnetic resonance techniques in multiple sclerosis: the present and the future. Archives of neurology. 2011;68(12):1514-20. 6. Rocca MA, Absinta M, Filippi $M$. The role of advanced magnetic resonance imaging techniques in primary progressive MS. Journal of neurology. 2012;259(4):611-21.

7. Rovaris M, Agosta F, Pagani E, Filippi M. Diffusion tensor MR imaging. Neuroimaging clinics of North America. 2009;19(1):37-43.

8. Schmierer K, Wheeler-Kingshott CA, Boulby PA, Scaravilli F, Altmann DR, Barker GJ, et al. Diffusion tensor imaging of post mortem multiple sclerosis brain. Neurolmage. 2007;35(2):467-77.

9. Rovaris M, Filippi M. Diffusion tensor MRI in multiple sclerosis. Journal of neuroimaging : official journal of the American Society of Neuroimaging. 2007;17 Suppl 1:27s-30s.

10. Kurtzke JF. Rating neurologic impairment in multiple sclerosis: an expanded disability status scale (EDSS). Neurology. 1983;33(11):1444-52.

11. Cutter GR, Baier ML, Rudick RA, Cookfair DL, Fischer JS, Petkau J, et al. Development of a multiple sclerosis functional composite as a clinical trial outcome measure. Brain : a journal of neurology. 1999;122 ( Pt 5):871-82.

12. Romme Christensen J, Ratzer R, Bornsen L, Lyksborg M, Garde E, Dyrby TB, et al. Natalizumab in progressive MS: results of an open-label, phase 2A, proof-of-concept trial. Neurology. 2014;82(17):1499-507. 13. Ratzer R, Romme Christensen J, Romme Nielsen B, Sorensen PS, Bornsen L, Sellebjerg F. Immunological effects of methylprednisolone pulse treatment in progressive multiple sclerosis. Journal of neuroimmunology. 2014;276(1-2):195-201.

14. Schreiber K, Magyari M, Sellebjerg F, Iversen P, Garde E, Madsen CG, et al. High-dose erythropoietin in patients with progressive multiple sclerosis: A randomized, placebo-controlled, phase 2 trial. Multiple sclerosis (Houndmills, Basingstoke, England). 2017;23(5):675-85.

15. Polman $\mathrm{CH}$, Wolinsky JS, Reingold SC. Multiple sclerosis diagnostic criteria: three years later. Multiple sclerosis (Houndmills, Basingstoke, England). 2005;11(1):5-12.

16. Benjamini Y, Hochberg Y. Controlling The False Discovery Rate - A Practical And Powerful Approach To Multiple Testing. Journal of the Royal Statistical Society. 1995;Series B(Methodological 57):289 - 300.

17. Yaldizli O, Pardini M, Sethi V, Muhlert N, Liu Z, Tozer DJ, et al. Characteristics of lesional and extralesional cortical grey matter in relapsing-remitting and secondary progressive multiple sclerosis: $\mathrm{A}$ magnetisation transfer and diffusion tensor imaging study. Multiple sclerosis (Houndmills, Basingstoke, England). 2016;22(2):150-9.

18. Giorgio A, Santelli L, Tomassini V, Bosnell R, Smith S, De Stefano N, et al. Age-related changes in grey and white matter structure throughout adulthood. Neurolmage. 2010;51(3):943-51.

19. Barkhof $F$. The clinico-radiological paradox in multiple sclerosis revisited. Current opinion in neurology. 2002;15(3):239-45. 
20. Lassmann $\mathrm{H}$. The pathologic substrate of magnetic resonance alterations in multiple sclerosis. Neuroimaging clinics of North America. 2008;18(4):563-76, ix.

21. Amann M, Papadopoulou A, Andelova M, Magon S, Mueller-Lenke N, Naegelin Y, et al. Magnetization transfer ratio in lesions rather than normal-appearing brain relates to disability in patients with multiple sclerosis. Journal of neurology. 2015;262(8):1909-17.

22. Ingle GT, Stevenson VL, Miller DH, Thompson AJ. Primary progressive multiple sclerosis: a 5-year clinical and MR study. Brain : a journal of neurology. 2003;126(Pt 11):2528-36.

23. Mottershead JP, Schmierer K, Clemence M, Thornton JS, Scaravilli F, Barker GJ, et al. High field MRI correlates of myelin content and axonal density in multiple sclerosis--a post-mortem study of the spinal cord. Journal of neurology. 2003;250(11):1293-301.

24. Schlaeger R, Papinutto N, Zhu AH, Lobach IV, Bevan CJ, Bucci M, et al. Association Between Thoracic Spinal Cord Gray Matter Atrophy and Disability in Multiple Sclerosis. JAMA neurology. 2015;72(8):897-904.

25. Penny S, Khaleeli Z, Cipolotti L, Thompson A, Ron M. Early imaging predicts later cognitive impairment in primary progressive multiple sclerosis. Neurology. 2010;74(7):545-52.

26. Kalkers NF, Bergers L, de Groot V, Lazeron RH, van Walderveen MA, Uitdehaag BM, et al. Concurrent validity of the MS Functional Composite using MRI as a biological disease marker. Neurology. 2001;56(2):215-9. 27. Schmierer K, Scaravilli F, Altmann DR, Barker GJ, Miller DH. Magnetization transfer ratio and myelin in postmortem multiple sclerosis brain. Annals of neurology. 2004;56(3):407-15.

28. Brochet B, Dousset V. Pathological correlates of magnetization transfer imaging abnormalities in animal models and humans with multiple sclerosis. Neurology. 1999;53(5 Suppl 3):S12-7.

29. Filippi M, Cercignani M, Inglese M, Horsfield MA, Comi G. Diffusion tensor magnetic resonance imaging in multiple sclerosis. Neurology. 2001;56(3):304-11.

30. Lyksborg M, Siebner HR, Sorensen PS, Blinkenberg M, Parker GJ, Dogonowski AM, et al. Secondary progressive and relapsing remitting multiple sclerosis leads to motor-related decreased anatomical connectivity. PloS one. 2014;9(4):e95540.

31. Kutzelnigg A, Lucchinetti CF, Stadelmann C, Bruck W, Rauschka H, Bergmann M, et al. Cortical demyelination and diffuse white matter injury in multiple sclerosis. Brain : a journal of neurology. 2005;128(Pt 11):2705-12.

32. Frischer JM, Bramow S, Dal-Bianco A, Lucchinetti CF, Rauschka H, Schmidbauer M, et al. The relation between inflammation and neurodegeneration in multiple sclerosis brains. Brain : a journal of neurology. 2009;132(Pt 5):1175-89.

\section{Highlights}

- $\mathrm{MRI}$ and disability in progressive MS, an extensive study

- Disability in progressive MS is associated with increased T2 lesion volume

- EDSS worsening in progressive MS is associated with reduced MTR in T2 lesions

- In progressive MS, MD in T2 lesions correlate with performance in T25FW and PASAT

$\begin{array}{lc}\text { Participants (women/total n) } & 52 / 93 \\ \text { MS type (PPMS/SPMS) } & 37 / 56 \\ \text { Age } & 50(45-54) \\ \text { Disease duration } & 9(5-15) \\ \text { Progression duration } & 6(3-9)\end{array}$


EDSS score

9HPT (sec)

T25FW (sec)

PASAT (number correct)
$5(4.5-6)$

$27.8(22.6-34.9)$

$8.8(6.1-13.4)$

$50(36 / 56)$

Table 1. Patient demographics. Participants and MS type are summarized in counts. Other variables are given as median values with interquartile ranges in brackets. All values are baseline values. Abbreviations: Primary progressive multiple sclerosis = PPMS; secondary progressive multiple sclerosis = SPMS; expanded disability status scale $=$ EDSS; 9 hole peg test = 9HPT; timed 25 foot walk = T25FW; paced auditory serial addition test $=$ PASAT.

\begin{tabular}{|c|c|c|c|c|c|c|c|c|c|c|c|c|c|c|c|}
\hline & \multicolumn{2}{|c|}{ Value } & \multicolumn{3}{|c|}{ Age } & \multicolumn{2}{|c|}{ Sex } & \multicolumn{2}{|c|}{ MS-type } & \multicolumn{3}{|c|}{ Disease duration } & \multicolumn{2}{|c|}{$\begin{array}{l}\text { Progression } \\
\text { duration }\end{array}$} & \multirow[b]{2}{*}{$q$} \\
\hline & Mean & SD & $r$ & $p$ & $q$ & $p$ & $q$ & $p$ & $q$ & $r$ & $p$ & $q$ & $r$ & $p$ & \\
\hline $\begin{array}{l}\text { Lesion } \\
\text { volume } \\
\star\end{array}$ & 5782 & $\begin{array}{l}(2101- \\
15266)\end{array}$ & 0.129 & $\begin{array}{c}0.24 \\
6\end{array}$ & $\begin{array}{c}0.61 \\
6\end{array}$ & 0.765 & $\begin{array}{c}1.27 \\
5\end{array}$ & $\begin{array}{c}0.01 \\
6\end{array}$ & 0.08 & 0.363 & 0.001 & 0.004 & 0.133 & $\begin{array}{c}0.23 \\
2\end{array}$ & $\begin{array}{c}0.46 \\
4\end{array}$ \\
\hline $\begin{array}{l}\text { MTR in } \\
\text { lesions }\end{array}$ & 31.91 & -2.723 & 0.07 & 0.53 & $\begin{array}{c}0.75 \\
7\end{array}$ & 0.271 & $\begin{array}{c}1.35 \\
5\end{array}$ & $\begin{array}{c}0.13 \\
9\end{array}$ & $\begin{array}{c}0.34 \\
9\end{array}$ & 0.314 & 0.004 & 0.006 & $\begin{array}{c}- \\
0.182\end{array}$ & $\begin{array}{c}0.09 \\
9\end{array}$ & $\begin{array}{c}0.98 \\
7\end{array}$ \\
\hline $\begin{array}{l}\text { FA in } \\
\text { lesions }\end{array}$ & 0.294 & -0.04 & $0 . \overline{235}$ & $\begin{array}{c}0.02 \\
8\end{array}$ & $\begin{array}{c}0.28 \\
5\end{array}$ & $0 ?$ & $\begin{array}{c}0.72 \\
1\end{array}$ & $\begin{array}{c}0.24 \\
3\end{array}$ & $\begin{array}{c}0.34 \\
8\end{array}$ & $\begin{array}{c}- \\
0.171\end{array}$ & 0.113 & 0.141 & 0.054 & $\begin{array}{c}0.62 \\
2\end{array}$ & $\begin{array}{c}0.69 \\
1\end{array}$ \\
\hline $\begin{array}{l}\text { MD in } \\
\text { lesions }\end{array}$ & $\begin{array}{c}1.14 \mathrm{E}- \\
09\end{array}$ & $\begin{array}{c}-1.22 \mathrm{E}- \\
10\end{array}$ & 0.207 & $\begin{array}{c}0.05 \\
4\end{array}$ & $\begin{array}{c}0.27 \\
2\end{array}$ & 0.973 & $\begin{array}{c}0.97 \\
3\end{array}$ & $\begin{array}{c}0.00 \\
3\end{array}$ & $\begin{array}{c}0.02 \\
7\end{array}$ & 0.454 & $\begin{array}{c}<0.00 \\
1\end{array}$ & $\begin{array}{c}<0.00 \\
1\end{array}$ & 0.163 & $\begin{array}{c}0.13 \\
1\end{array}$ & $\begin{array}{c}0.65 \\
6\end{array}$ \\
\hline $\begin{array}{l}\text { MTR in } \\
\text { NAWM }\end{array}$ & 38.7 & -1.096 & $0 . \overline{079}$ & 0.48 & $\begin{array}{c}0.95 \\
9\end{array}$ & 0.879 & $\begin{array}{c}0.97 \\
7\end{array}$ & $\begin{array}{c}0.09 \\
6\end{array}$ & $\begin{array}{c}0.32 \\
1\end{array}$ & $\begin{array}{c}- \\
0.344\end{array}$ & 0.001 & 0.004 & $\begin{array}{c}- \\
0.156\end{array}$ & $\begin{array}{c}0.15 \\
9\end{array}$ & $\begin{array}{c}0.39 \\
9\end{array}$ \\
\hline $\begin{array}{l}\text { FA in } \\
\text { NAWM }\end{array}$ & 0.353 & -0.026 & 0.042 & $\begin{array}{c}0.70 \\
1\end{array}$ & $\begin{array}{c}0.87 \\
6\end{array}$ & 0.871 & $\begin{array}{c}1.08 \\
9\end{array}$ & $\begin{array}{l}0.19 \\
2\end{array}$ & $\begin{array}{c}0.31 \\
9\end{array}$ & 0.318 & 0.003 & 0.005 & $\begin{array}{c}- \\
0.111\end{array}$ & $\begin{array}{c}0.30 \\
6\end{array}$ & $\begin{array}{c}0.43 \\
8\end{array}$ \\
\hline $\begin{array}{l}\text { MD in } \\
\text { NAWM }\end{array}$ & $\begin{array}{c}7.56 \mathrm{E}- \\
10\end{array}$ & $\begin{array}{c}-2.97 \mathrm{E}- \\
11\end{array}$ & 0.075 & $\begin{array}{c}0.48 \\
8\end{array}$ & $\begin{array}{c}0.81 \\
3\end{array}$ & 0.85 & $\begin{array}{c}1.21 \\
4\end{array}$ & $\begin{array}{c}0.56 \\
7\end{array}$ & $\begin{array}{c}0.63 \\
1\end{array}$ & 0.235 & 0.028 & 0.041 & 0.04 & 0.71 & 0.71 \\
\hline $\begin{array}{l}\text { MTR in } \\
\text { CGM }\end{array}$ & 31.1 & -0.824 & 0.038 & $\begin{array}{c}0.73 \\
5\end{array}$ & $\begin{array}{c}0.81 \\
6\end{array}$ & 0.274 & $\begin{array}{c}0.91 \\
5\end{array}$ & $\begin{array}{c}0.09 \\
6\end{array}$ & $\begin{array}{c}0.32 \\
1\end{array}$ & $\begin{array}{c}- \\
0.149\end{array}$ & 0.178 & 0.178 & $\overline{-}-$ & $\begin{array}{c}0.24 \\
8\end{array}$ & $\begin{array}{c}0.41 \\
3\end{array}$ \\
\hline $\begin{array}{l}\text { FA in } \\
\text { CGM }\end{array}$ & 0.134 & -0.009 & 0.016 & 0.88 & 0.88 & $\begin{array}{c}<0.00 \\
1\end{array}$ & $\begin{array}{c}0.00 \\
2\end{array}$ & $\begin{array}{c}0.75 \\
5\end{array}$ & $\begin{array}{c}0.75 \\
5\end{array}$ & $\begin{array}{c}- \\
0.164\end{array}$ & 0.128 & 0.143 & 0.067 & $\begin{array}{c}0.53 \\
5\end{array}$ & $\begin{array}{c}0.66 \\
9\end{array}$ \\
\hline $\begin{array}{l}\text { MD in } \\
\text { CGM }\end{array}$ & $\begin{array}{c}9.49 \mathrm{E}- \\
10\end{array}$ & $\begin{array}{c}-5.61 \mathrm{E}- \\
11\end{array}$ & 0.17 & $\begin{array}{c}0.11 \\
5\end{array}$ & $\begin{array}{c}0.38 \\
3\end{array}$ & 0.414 & $\begin{array}{c}0.82 \\
7\end{array}$ & $\begin{array}{c}0.17 \\
8\end{array}$ & $\begin{array}{c}0.35 \\
5\end{array}$ & 0.35 & 0.001 & 0.003 & 0.161 & $\begin{array}{c}0.13 \\
5\end{array}$ & $\begin{array}{c}0.45 \\
1\end{array}$ \\
\hline
\end{tabular}

Table 2. MRI measures and associations with demographics in the cross-sectional cohort. ${ }^{*} T 2$ Lesion volume is median value with interquartile range in brackets. Remaining MRI values are given as means with standard deviations in brackets. Pearson's correlation coefficients ( $r$ ) are shown for age, disease duration and progression duration. Student's t-test is used for sex and MS type. In all analyses, logarithmically transformed values for lesion volume were used. Q-values are $p$-values that were false discovery rate corrected for multiple comparisons. Abbreviations: SD = Standard deviation; Magnetisation transfer ratio = MTR; fractional anisotropy = FA; mean diffusivity = MD; normal appearing white matter = NAWM; cortical grey matter = CGM.

\begin{tabular}{|c|c|c|c|c|c|c|c|c|c|c|c|c|}
\hline & \multicolumn{3}{|c|}{ EDSS } & \multicolumn{3}{|c|}{ 9HPT } & \multicolumn{3}{|c|}{ T25FW } & \multicolumn{3}{|c|}{ PASAT } \\
\hline & $\rho$ & $p$ & $q$ & $\rho$ & $p$ & $q$ & $\rho$ & $p$ & $q$ & $\rho$ & $\mathrm{p}$ & $q$ \\
\hline T2 Lesion volume & 0.286 & 0.009 & 0.043 & 0.312 & 0.006 & 0.041 & 0.313 & 0.006 & 0.047 & -0.303 & 0.008 & 0.044 \\
\hline
\end{tabular}




$\begin{array}{llllllllllllll}\text { MTR in lesions } & -0.278 & \mathbf{0 . 0 1 1} & \mathbf{0 . 0 4 8} & -0.323 & \mathbf{0 . 0 0 4} & 0.056 & -0.165 & 0.152 & 0.225 & 0.094 & 0.418 & 0.478 \\ \text { FA in lesions } & 0.066 & 0.544 & 0.588 & 0.069 & 0.546 & 0.575 & -0.104 & 0.359 & 0.423 & 0.215 & 0.057 & 0.120 \\ \text { MD in lesions } & 0.196 & 0.069 & 0.132 & 0.188 & 0.096 & 0.174 & 0.278 & \mathbf{0 . 0 1 2} & \mathbf{0 . 0 4 9} & -0.356 & \mathbf{0 . 0 0 1} & \mathbf{0 . 0 2 5} \\ \text { MTR in NAWM } & -0.212 & 0.054 & 0.120 & -0.312 & \mathbf{0 . 0 0 6} & 0.057 & -0.191 & 0.096 & 0.167 & 0.266 & \mathbf{0 . 0 2 0} & 0.062 \\ \text { FA in NAWM } & -0.248 & \mathbf{0 . 0 2 0} & 0.058 & -0.359 & \mathbf{0 . 0 0 1} & \mathbf{0 . 0 4 3} & -0.270 & \mathbf{0 . 0 1 6} & 0.052 & 0.182 & 0.109 & 0.181 \\ \text { MD in NAWM } & 0.124 & 0.252 & 0.336 & 0.254 & \mathbf{0 . 0 2 3} & 0.062 & 0.079 & 0.487 & 0.541 & -0.125 & 0.273 & 0.352 \\ \text { MTR in CGM } & -0.118 & 0.286 & 0.347 & -0.225 & \mathbf{0 . 0 4 9} & 0.115 & -0.138 & 0.232 & 0.320 & 0.127 & 0.276 & 0.345 \\ \text { FA in CGM } & -0.150 & 0.166 & 0.236 & -0.253 & \mathbf{0 . 0 2 3} & 0.059 & -0.059 & 0.606 & 0.621 & 0.003 & 0.976 & 0.976 \\ \text { MD in CGM } & 0.166 & 0.125 & 0.192 & 0.273 & \mathbf{0 . 0 1 4} & 0.051 & 0.209 & 0.062 & 0.124 & -0.180 & 0.113 & 0.180\end{array}$

Table 3. Relationship between MRI and clinical disability. Spearman's correlation coefficient $(\rho)$ and $p$ values are calculated for all correlations. Q-values are $p$-values that were false discovery rate corrected for multiple comparisons. Bolded values are significant with $p$ or $q$ values $<0.05$. Abbreviations: Expanded disability status scale $=$ EDSS; 9 hole peg test $=9 \mathrm{HPT}$; timed 25 foot walk = T25FW; paced auditory serial addition test $=$ PASAT; Magnetisation transfer ratio $=$ MTR; fractional anisotropy = FA; mean diffusivity $=$ MD; normal appearing white matter $=$ NAWM; cortical grey matter $=$ CGM . 